\title{
RELAÇÕES ENTRE CULTURA E ENSINO um olhar discursivo sobre as políticas públicas para formação de professores
}

\author{
Fabiele Stockmans De Nardi \\ Fabíola Ponzoni Balzan
}

RESUMO: Notre but dans cet article est d'observer la notion de culture mobilisée dans un document sur le programme destiné aux enseignants des écoles élémentaires. Le point de départ est une discussion de la notion de culture, que nous avons pris comme un lieu d'interpretation, pour observer les contradictions qui traversent la proposition même de culture, parfois en réaffirmant son caractère dynamique, parfois en supposant des mouvements de neutralisation dans ces relations entre la culture et les environnements éducatifs. Cette analyse permet de réaffirmer la complexité de la relation entre le sujet et la culture, surtout quand on considere la place destinée à la culture dans les processus d'ensegnement et d'apprentissage, et permet aussi une réflexion sur les relations de pouvoir impliquées dans le développement de la construction des connaissances.

PALAVRAS-CHAVE: cultura, sujeitos, ensino-aprendizagem.

A preocupação com as questões relacionadas à cultura e com o modo de abordarmos esse conceito tem sido uma constante nos trabalhos que se dedicam a pensar a educação e, também, a formação de professores. Isso se repete no documento Indagações sobre currículo. Trata-se de um conjunto de textos que abordam cinco eixos relacionados ao currículo. Nesse trabalho, analisaremos o volume intitulado ${ }^{1}$ Currículo, Conhecimento e Cultura, de Antonio Flávio Moreira e Vera Maria Candau, onde a questão da cultura aparece, como se pode perceber pelo título, de maneira destacada.

Mas do que falamos quando nos referimos à cultura? Esse questionamento, que decorre em parte de um esvaziamento de sentidos que pode gerar o uso por vezes indiscriminado desse conceito, leva-nos a propor, inicialmente, uma breve discussão sobre o conceito de cultura. Entendemos esse como um movimento fundamental, especialmente se pensarmos que tal esvaziamento provoca efeitos significativos, como temos defendido, não só para os saberes construídos em torno da noção, mas também sobre nossas práticas, que implicam tomadas de posição acerca da cultura.

Partimos, portanto, da consideração da cultura como um conceito de arredias fronteiras, reafirmando sua complexidade e natureza esquiva, para pensar a relação

\footnotetext{
Professora Adjunta do Departamento de Letras da Universidade Federal de Pernambuco na área de Língua Espanhola.

Coordenadora do Curso de Pedagogia da Faculdade Anglo-Americano e Doutorando do Programa de Pós-graduação em Educação da Universidade Federal do Rio Grande do Sul.

Embora nossa análise se centre especialmente no volume mencionado, faremos referência a fragmentos que compõem a introdução do referido documento e que é comum a todos os volumes.
} 
entre cultura e ensino. A análise que propomos se centrará sobre o modo como, nesse documento, esse olhar sobre a cultura é construído quando se trata de falar a/para professores sobre sua atuação em ambientes educativos. Ao fazer isso, no entanto, não foi possível deixar de observar como se produz, também, discursivamente, a relação entre o especialista, ou seja, aquele que elabora esse documento, e o professor, a quem o texto é dirigido, na construção do conhecimento, e as contradições que emergem nesse dizer sobre a cultura.

\section{TAMBÉM NA CULTURA HÁ SEMPRE ALGO QUE FALHA}

Quero sobretudo evitar a impressão, muito difundida hoje em dia, de que já temos as respostas. Michel Pêcheux ${ }^{2}$

A primeira dificuldade daquele que se propõe a falar sobre cultura talvez seja a necessidade de definir o termo, de encontrar sua especificidade. Essa é certamente uma dificuldade da qual partilhamos e que nos fez começar, como muitos o fizeram, a definir cultura falando sobre aquilo a que, do ponto de vista que adotamos nesse trabalho, não se pode restringir essa noção. Iniciamos, portanto, por duas diferenciações: entre a cultura e as manifestações culturais, e a entre cultura e tradição.

É comum, ao falarmos sobre cultura, identificarmos o conceito com um conjunto de objetos que dela podem ser representativos. Teríamos, por exemplo, como cultura, um somatório de obras consagradas, que determinariam, então, pelo seu conhecimento, aqueles que da cultura fazem (ou não) parte. Os elementos que compões tais conjuntos, entendemos, devem ser vistos como manifestações culturais, produtos da cultura, que, no entanto, não se reduz a eles, visto tratar-se de um conceito necessariamente mais amplo e complexo.

Tampouco se pode confundir cultura e tradição, onde vive o que da cultura se sedimentou. Olhar apenas para a tradição, tomando-a como um sinônimo de cultura, é correr o risco de apagar o fato de que movimentos sociais e históricos estão intimamente ligados com os processos culturais, que, portanto, vivem a modificar-se, (re)significar-se. Isso exige compreender que a cultura é essencialmente dinâmica, e como tal, para além da repetição, comporta espaços de ruptura. Cultura é lugar de sujeitos, que se movem nas redes sociais produzindo nós e fazendo furos, portanto, também não é a cultura aquisição ou transferência de algo que está fora do sujeito, que lhe é exterior, porque ela é o lugar em que se organiza a relação desse sujeito com o Outro.

Sendo assim, longe da fixidez, tão indesejável também quando pensamos a educação, é necessário olhar para a cultura como um espaço de liberdade, nos termos de Eagleton (2005, p.14), "uma tensão entre fazer e ser feito, racionalidade e espontaneidade". Por isso entendemos a cultura como um lugar de interpretação, de subversão, de compreensão do outro e de seu espaço (e, portanto, de nosso próprio espaço e dos lugares que nele encontrarmos para sermos sujeitos dessa cultura). Esse olhar se apóia na consideração de que a cultura permeia os processos identificatórios por que passam os sujeitos, como mencionamos acima ao falar desse espaço em que se organiza a relação do sujeito com o Outro. O sujeito mergulha na cultura assim como na linguagem, inserção que é condição necessária para que construa um lugar de dizer,

PÊCHEUX, 1996, p. 148 
encontre a possibilidade de dizer, e que determina os gestos de interpretação que esse sujeito irá produzir.

Ao retomar o texto de Freud, Fuks (2003, p.10) observará como, ao analisar psicanaliticamente a noção de cultura, o autor a situará no espaço entre "a interioridade de uma situação individual [...] e a exterioridade de um código universal, subjacente aos processos de subjetivação e aos regulamentos das ações do sujeito com o outro". É de uma subjetividade que se constrói e exerce no espaço social que falamos, portanto, ao recorrermos à cultura, tomada então como espaço simbólico. E nisso reside também a força da afirmação de que não há sujeito sem cultura, justamente porque é pela via da língua-cultura que se dá sua inserção nas redes de sentido.

Podemos dizer, desse modo, que nos assujeitamos a uma cultura, "mergulho" que não é, no entanto, da ordem do puramente consciente, tampouco se dá por completo. Pechêux (1996, p.148), ao falar sobre $O$ mecanismo do (des)conhecimento ideológico, comenta:

Permitam-me apenas ressaltar que o traço comum a essas duas estruturas, respectivamente chamadas de ideologia e inconsciente, é o fato de elas operarem ocultando sua própria existência, produzindo uma rede de verdades 'subjetivas' evidentes, com o 'subjetivas' significando, aqui, não 'que afetam o sujeito', mas 'em que o sujeito se constitui.

É a esse funcionamento comum, que Pêcheux identifica ao relacionar ideologia e inconsciente, que queremos remeter ao falar de um assujeitamento à cultura, o que nos permite pensá-la como uma estrutura-funcionamento que não se confunde com elas, mas que opera de maneira semelhante a essas ordens. A cultura trabalha naturalizando aquilo que, no entanto, é produto de um trabalho social.

E também na relação do sujeito com a cultura algo falha, porque ela é marcada por espaços de pertencimento e de interdição. Sustenta esse desejo de "dominar a cultura" a aceitação de que possamos falar de uma unidade cultural, ou seja, de um sistema cultura homogêneo, que não comporte cisões. A crença, portanto, na possibilidade de que o sujeito possa dominar uma cultura, a sua ou a do outro, se forja a partir desse olhar a cultura como um campo facilmente delimitável, negando que há um impossível na cultura, o qual se traduz como a impossibilidade de que o sujeito venha a partilhar da totalidade daquilo que entendemos como um sistema cultural.

Nossa participação numa cultura é sempre parcial, porque há lugares que permanecem interditados para o sujeito, mesmo que ele se identifique com esse sistema, que em seu próprio interior cria funcionamentos de exclusão. Por isso a ideia de domínio é contrária à própria dinâmica da cultura, que, assim como a língua, não se entrega ao sujeito para que esse possa apreendê-la, mas o acolhe (ou não) justamente por comportar, em seu interior, o espaço da diferença, da contradição.

Homogeneizar a cultura, compreendê-la como um campo estabilizado, é tomá-la como um espaço de reafirmação de um estado de coisas, e não como um lugar do novo, da resistência. Pensar a cultura como uma estrutura-funcionamento que resiste á dominação, pensar a resistência na/da cultura é justamente o que garante o seu caráter crítico. Por isso recusar a afirmação da cultura como um conjunto restrito de manifestações é tão importante, assim como reafirmar o espaço da pluralidade nos ambientes educativos, porque essa é, entendemos, a possibilidade de que haja pertencimento e não apenas exclusão.

Quando falamos dessa resistência na/da cultura, referimo-nos à sua dimensão política, e, portanto, também histórico-social. São elas que garantem à cultura a possibilidade de ser dinâmica e crítica. Também sobre isso pensou Chauí (2006), quando se referiu à cultura como a capacidade de decifrar as formas de produção social 
da memória e do esquecimento, possibilitando, portanto, que outras práticas venham a se construir. A "cultura exige certas condições sociais, e já que essas condições podem envolver o Estado, pode ser que ela também tenha uma dimensão política", disse Eagleton (2005, p.21), para quem a "cultura vai de mãos dadas com o intercurso social". Ao analisar historicamente os aspectos normativo e descritivo sempre atrelados às noções de civilização e cultura ${ }^{3}$, o que marca Eagleton é que o modo de olharmos para esses conceitos implica, sempre, pensar em sua história e, portanto, também nos juízos de valor que inevitavelmente os acompanham, a que poderíamos acrescentar, acompanham também as práticas que sobre essas concepções se estabelecem.

Sem nos alongarmos mais nessa discussão, podemos dizer que nos cabe afirmar a proximidade entre cultura e política ${ }^{4}$, já que nenhuma posição em relação à cultura é neutra e seus efeitos, em especial quando se trata de pensar a elaboração dos currículos na escola, faz-se sentir de forma muito clara no modo como espaços de dizer são abertos e/ou interditados aos sujeitos (a alguns sujeitos). Também é preciso olhar para o ensino-aprendizagem enquanto práticas políticas, enquanto espaços de dinamização de políticas, ou seja, de regulação e de (re)direcionamento de práticas didáticopedagógicas. Porque é isso, como veremos mais adiante, que faz o texto da lei e também o texto do especialista, já que esse último, ainda que nem sempre de forma prescritiva, aparece como a voz dominante, a voz do saber, aquela que pode indicar os caminhos a seguir.

Recuperar a dimensão política da cultura é, portanto, deixar de olhar para esse espaço como um lugar de observação de registros inertes, diante dos quais não pode o sujeito produzir outros movimento que não aqueles do reconhecimento e da aceitação.

\section{DIZERES SOBRE A CULTURA, O ENSINO E O PROFESSOR}

As arredias fronteiras da noção de cultura e a complexidade que implica pensar esse conceito e sua operacionalização no processo de ensino-aprendizagem poderiam colocar em questão a insistência de pensar essa relação. É impossível negarmos, no entanto, o interesse de tal discussão e, no caso específico desse trabalho, tal interesse justifica-se, ainda, conforme já comentamos, pelo fato de que grande parte dos materiais produzidos pelo MEC, os quais sustentam políticas de formação de professores em todo território nacional, afirmarem que a educação acontece relacionada intimamente com a cultura.

SD1 - Levando em consideração que o processo educativo é complexo e fortemente marcado pelas variáveis pedagógicas e sociais, entendemos que esse não pode ser analisado fora da interação dialógica entre escola e vida, considerando $o$ desenvolvimento humano, o conhecimento e a cultura. (MOREIRA; CANDAU, 2008 , p. $\left.6^{5}\right)$.

\footnotetext{
3 Explora-se de forma mais pontual essa relação entre civilização e cultura em De Nardi (2007).

4 Tudo o que afirmamos até o momento não implica negar a dimensão estética inerente à relação dos sujeitos com o que chamamos de "objetos culturais", tampouco fazê-lo em relação ao caráter formativo que pode ter o estudo daquilo que se consagrou como parte de uma tradição. Muito pelo contrário. Importa, no entanto, observar a posição que tomamos diante desses objetos, que serão, nessa perspectiva, nossos objetos de análise e não apenas de contemplação; e mais, observar, como expusemos anteriormente, o funcionamento dessa relação sujeito-cultura, que passa pela identificação desse sujeito com os sistemas culturais de que se aproxima.

Esse fragmento corresponde à apresentação do conjunto de texto, ou seja, é comum a todos os volumes e de responsabilidade do Ministério da Educação.
} 
O documento em análise, ao tratar do currículo, remete à fixação de conteúdos mínimos/diretrizes curriculares para o Ensino Fundamental, determinada pela Constituição Federal de 1988, "de maneira a assegurar a formação básica comum e o respeito aos valores culturais e artísticos, nacionais e regionais", obrigação do estado que se efetiva por meio de instrumentos diversos, como os PCNs; mas coloca sob a responsabilidade da escola (e mais especificamente dos professores), a organização do currículo, tarefa para a qual o conjunto de textos em questão é apresentado como subsídio para a discussão.

Depois de relatar o longo caminho percorrido por esses textos - ou seja, organizações e conselhos vinculados ao Ministério da Educação, além de seminários reunindo autoridades e "educadores, professores, gestores e pesquisadores sobre o currículo" - o texto de apresentação do documento, elaborado pela Secretaria de Educação Básica (MEC), o declara, então, entregue aos professores, a quem cabe a tarefa de responder às indagações propostas.

A lei e os especialistas dizem o que fazer, ao professor cabe responder como fazer através de uma prática didático-pedagógica transformadora, anunciada amplamente no documento. Esse relato das instâncias percorridas não é, portanto, algo aleatório, já que cria o efeito de legitimação desse dizer, e, portanto, produz, de certo modo, o lugar do professor como o lugar daquele que precisa escutar, que deve escutar e aprender para agir. Há uma tentativa de suavizar esse caráter instrucional, convocando o professor ao diálogo, mas ainda assim há uma voz que se impõe, nesse caso a do especialista, e se impõe justamente pelo modo como se constrói a legitimidade do documento em análise e o encaminhamento de sua leitura. Há, portanto, um jogo de forças que é desigual e que, por isso mesmo, provoca uma ruptura no anunciado desejo de construção de um efetivo diálogo.

Essa divisão do trabalho entre o especialista e o educador, embora suavizado por um marcado desejo de problematização em lugar de prescrição, aparece de forma interessante no texto de Moreira e Candau, a exemplo do que segue:

SD2 - O papel do educador no processo curricular é, assim, fundamental. Ele é um dos grandes artífices, queira ou não, da construção dos currículos que se materializam nas escolas e nas salas de aula. Daí a necessidade de constantes discussões, na escola, sobre o currículo [...]. Daí nossa obrigação, como profissionais da educação, de participar crítica e criativamente na elaboração de currículos mais atraentes, mais democráticos, mais fecundos. (MOREIRA; CANDAU, 2008, 19 - grifo nosso)

Embora aquele que enuncia se coloque aqui como parte do processo, enquanto profissional da educação ${ }^{6}$, não é ele o artífice, o que executa; esse é o papel do outro, do educador, daquele para quem se fala (não necessariamente com quem se fala). Essa oscilação entre o nós e o eles, marca, entendemos, a divisão do trabalho na elaboração do currículo e reforça o papel de executor do professor que está na escola e que é, às vezes, incluído nesse nós que se compromete e acolhe e, outras, convidado a ouvir,

\footnotetext{
6 É interessante perceber que essa designação "profissionais da educação" aparece reiteradamente no texto quando o que se quer reforçar é o caráter de construção coletiva do documento. Na apresentação do documento, p. 14, encontramos, por exemplo: "A quem cabe captar essas indagações e trabalhá-las? A todo o coletivo de profissionais do sistema escolas, professores, coordenadores pedagógicos, diretores, dirigentes municipais e estaduais, profissionais das Secretarias e do MEC. (...)”. No entanto, "as indagações" a que se refere o documento já estão sendo nele apresentadas, para que sejam reconhecidas e discutidas, o que pressupões que a coletividade do trabalho não se produz de forma idêntica em todas as instância, ou para todos esses profissionais Tanto que se lê, em seguida, que o texto apresentado pretende "contribuir com o profissionalismo de professoras e professores da Educação Básica”.
} 
como quando em lugar de se falar ao professor se convida a que alguém sensibilize o corpo docente ${ }^{7}$. Mas não era com ele que se estava falando? A quem, então, cabe o papel de sensibilizar?

Há que se pensar, portanto, que lugar é esse que se produz para o professor, porque parece que muitas vezes no afã de "formar", "qualificar", cai-se no engano de fazer com que a exigência de uma nova postura, sobre a qual tanto insistem os textos ofertados aos professores, não seja também assumida por aquele que com ele se dispõe a conversar. Como bem lembrou Bertoldo (2007, p.45), é arriscado partir do pressuposto de que a conscientização do professor constitui condição suficiente para que transformações positivas ocorram. Quando fazemos isso, negamos a dimensão inconsciente desse sujeito, pressupondo que seu esclarecimento seria capaz de dar a ele a liberdade necessária para agir, para construir o novo, como se esse sujeito pudesse substituir, de imediato, todas as práticas que, nesse caso específico, o fizeram professor.

É como se nesse desejo de "formar", de dar a conhecer, se apagasse o fato de que falamos de um sujeito que é um ser-em-falta. Ou seja, falamos de um sujeito constituído pelo/no discurso e, portanto, pelas/nas práticas que o dizem professor. Por isso, se retomarmos a questão do artífice, do professor como aquele a quem cabe a execução de um projeto, esse dizer do especialista se constrói como um espaço de saber, de um saber sobre o fazer educativo, sobre o que fazer, que em lugar de fazer a aproximação teoria-prática, reforça essa cisão ao reforçar a divisão do trabalho. Esse saber "sobre" que historicamente se repete em relação às práticas escolares, faz com que nesse material, mesmo havendo uma explicitação das posições teórico-políticas assumidas por aquele que se coloca como autor do texto, esse dizer se apresente como algo da ordem do inquestionável, efeito reforçado pela trajetória da reflexão como um relato de legitimação. E aí deslizamos novamente para a construção do professor como aquele a quem só cabe a execução: identificar o que fazer e construir a melhor maneira de fazê-lo. Nesse sentido é interessante voltarmos à Introdução do documento, elaborada pela Secretaria de Educação Básica, para olhar seus parágrafos finais:

SD3 - Como ler e trabalhar os textos?

Na especificidade de cada coletivo, escola e sistema, esses eixos poderão ser desdobrados, alguns serão mais enfatizados. Outras indagações poderão ser acrescentadas. Esse poderá ser um exercício dos coletivos. No conjunto de textos, prevalece um trato dialogal, aberto, buscando incentivar esse exercício de cultivar sensibilidades teóricas e pedagógicas para identificar e ouvir indagações que vêm das teorias e práticas e para apontar reorientações.

Cada texto pode ser lido e trabalhado separadamente e sem uma ordem seqüenciada. Cada eixo tem seus significados. Entretanto, será fácil perceber que as indagações dos diversos textos se reforçam e se ampliam. Na leitura do conjunto, será fácil perceber que há indagações que são constantes, que fazem parte da dinâmica de nosso tempo. Um exercício coletivo poderá ser perceber essas indagações mais constantes e instigantes, ver como se articulam e se reforçam entre si. Perceber essas articulações será importante para tratar o currículo e as práticas educativas das escolas como um todo e como propostas coesas de formação de educandos e educadores. Captar o que há de mais articulado no conjunto das indagações auxiliará a superar estilos recortados e fragmentados das propostas curriculares, de abordagens do conhecimento e dos processos de ensino aprendizagem. (p. 15)

\footnotetext{
7 "Em casos como esse, pode ser útil, em um primeiro momento, buscarmos sensibilizar o corpo docente para a pluralidade e para a diversidade."(31)
} 
O que retorna, nesse momento, é o embate entre uma insistência nessa autonomia de leitura do professor e seu grupo - já que se trata de um material "dialogal, aberto"-, e a instrução clara, trazida sob a forma de um questionamento, de como isso deve ser feito. Mesmo que se insista no uso de "pode" em lugar de "deve", a indicação de como fazer essa leitura aparece em construções diretas, muitas vezes curtas, que reforçam o efeito instrucional desse dizer.

Esse caráter se intensifica quando encontramos um fácil repetido em relação ao que deve ser identificado/percebido: "será fácil perceber que as indagações dos diversos textos se reforçam e se ampliam. Na leitura do conjunto, será fácil perceber que há indagações que são constantes". Esse fácil, colado às "indagações", nos alerta para o fato de que percebê-las não é uma possibilidade, mas uma obrigação do professor, que está recebendo um material coeso e precisa saber utilizá-lo para "superar estilos recortados e fragmentados das propostas curriculares".

Há uma separação entre o teórico e o didático-pedagógico, e uma certeza reafirmada de que o "esclarecimento", recebido por meio do especialista, é uma garantia de que serão superados os problemas identificados (no caso, por esse mesmo especialista) nas práticas pedagógicas. Entendemos que há uma necessidade de se olhar com mais cuidado para essa divisão do trabalho entre o especialista e o artífice, e questionar o esclarecimento e/ou a conscientização como condições suficientes para uma efetiva alteração nas práticas dos sujeitos com/sobre quem falamos.

No entanto, não é possível negar que propiciar ao professor esse caminhar por espaços teóricos diversos é também um movimento necessário para que ele possa sair do seu lugar e vislumbrar a possibilidade de andar por outros espaços, de cultivar outras práticas, já que é também pela insistência do dizer que outros sentidos se fazem possíveis. Nesse sentido, o documento em análise traz contribuições importantes, uma vez que torna efetivo o compromisso de não apenas transmitir conceitos, mas, ainda que de forma inicial, elaborá-los.

Moreira e Candau, responsáveis pelo volume em análise, fazem um interessante caminho, por exemplo, no sentido de levar à elaboração da relação entre currículo e cultura. Recuperam, ainda que de forma breve, os (des)caminhos do conceito de cultura, pontuando as determinações históricas que levaram a se tornar, uma ou outra concepção, hegemônica, e seus possíveis reflexos no currículo. Colocam, assim, à mostra os desdobramentos que diferentes posturas têm sobre o cotidiano escolar, ressaltando-se, especialmente, nesse trabalho, as relações de poder implicadas na construção dos conhecimentos escolares e na determinação dos sentidos de cultura, que os autores exemplificam ao citar a distribuição do tempo/espaço destinado ao estudo de cada disciplina na escola.

SD4 - [...] o processo de construção do conhecimento escolar sofre, inegavelmente, efeitos de relações de poder. [...] a "hierarquia" que se encontra no currículo, com base na qual se valorizam diferentemente os conhecimentos escolares e se "justifica" a prioridade concedida à matemática em detrimento da língua estrangeira ou da geografia, deriva, certamente, de relações de poder. [...]

Nessa hierarquia, separam-se a razão e a emoção, a teoria e a prática, o conhecimento e a cultura. Nessa hierarquia legitimam-se saberes socialmente reconhecidos e estigmatizam-se saberes populares. [...]. (MOREIRA; CANDAU, 2008, p. 35 - grifo nosso).

Numa direção contrária, os autores insistem na dimensão simbólica da cultura, $o$ que a cultura faz, em vez do que a cultura é, ou seja, afirmam o caráter de prática social 
do conceito e, assim, o currículo como um espaço de tensão, de negociação de espaços, de produção de sentidos. Tensão que precisa ser assumida e não apagada, sem a qual, diríamos, não há espaço para a cultura enquanto lugar de interpretação.

Esse caráter crítico que se atribui à cultura, enquanto possibilidade de olhar para a diversidade leva os autores a trabalharem com o conceito de "daltonismo cultural", que exploram para mostrar a negação da diversidade como uma tentativa de homogeneizar o espaço escolar e a prática pedagógica, tornando idênticos os que são diferentes e apagando, em última análise, o caráter dialógico que envolve a própria construção dos conhecimentos nos espaços educativos.

SD5 - Em resumo, a ruptura do daltonismo cultural e da visão monocultural da dinâmica escolar é um processo pessoal e coletivo que exige descontruir e desnaturalizar estereótipos e "verdades" que impregnam e configuram a cultura escolar e a cultura da escola." (MOREIRA; CANDAU, 2008, p.32 - grifo nosso).

No entanto, é interessante observar um trecho, em que aparece uma discussão sobre os espaços educativos. Vejamos:

SD6 - Cabe também ressaltar a significativa influência exercida junto às crianças e aos adolescentes que povoam nossas salas de aula, pelos "currículos" por eles "vividos" em outros espaços sócio-educativos (...), nos quais se fazem sentir com intensidade muitos dos complexos fenômenos associáveis ao processo de globalização que hoje vivenciamos. (...) Vale perguntar: como temos, nas salas de aula, reagido a esse "confuso" panorama em que a diversidade se faz tão presente? Como temos nos esforçado para desestabilizar privilégios e discriminações? Como temos buscado neutralizar influências "indesejáveis"? Como temos, na escola, dialogado com os "currículos" desses espaços? (MOREIRA; CANDAU, 2008, p. 29 - grifo nosso)

Nossa inquietação em relação a essa fala reside no fato de que, ao mesmo tempo em que há um movimento no sentido de ampliar a noção de espaço educativo, de ampliar as fronteiras desse espaço, o que resultaria num caminhar para a construção de um conceito de cultura e, e, portanto, de um currículo que permitisse justamente pensar a heterogeneidade como inerente a ela, ou seja, pensar a cultura como espaço do diverso, atravessa esse dizer - como uma pergunta, mas com a força de uma afirmação -, esse "neutralizar influências indesejáveis".

E nossa inquietação, nesse momento, foi da ordem do incômodo, de uma impossibilidade de fazer laço entre um dizer que anuncia uma quase exigência - não uma opção - de que a escola olhe para os outros espaços e sua diversidade, isto é, seja capaz de efetivamente acolher a complexidade dos espaços sociais, um discurso que insiste, por exemplo, no currículo como uma construção histórica, como um espaço de poder, mas se permite perguntar "Como temos buscado neutralizar influências "indesejáveis?". Que influências? Como neutralizar? Por que ou para quem são indesejáveis as mencionadas influências?

E nesse momento só nos restaram mesmo perguntas: Convocamos a cultura, ou uma cultura, ou manifestações culturais para os espaços educativos para aceitá-las, cultuá-las, recusá-las e/ou neutralizar essa cultura ou suas manifestações? A dimensão crítica da cultura, de que tão bem falou Chauí, não reside justamente na tentativa de nos afastarmos tanto do culto quanto do desejo de neutralização para buscar compreender a cultura? Não se instauraria, nesse dizer a cultura, um confronto/conflito pela 
contradição entre esse desejo de neutralizar "influências indesejáveis" e o "respeito ${ }^{8}$ aos valores culturais e artísticos" que o documento menciona ao citar a Constituição Federal? Não seria, mais interessante, nesse caso, pensarmos em "desconstruir" em lugar de "neutralizar"?

\section{MAIS DO QUE RESPOSTAS, PROPOSIÇÕES FINAIS}

Legitimação e relações de poder. É interessante perceber, ao olhar para esses dizeres acerca da relação entre o professor e o especialista, e do espaço da cultura nos ambientes educativos que relacionamos acima, como se constrói um olhar crítico sobre os efeitos das relações de poder na construção do conhecimento, as quais determinam tanto que 'hierarquias' sejam criadas, quanto que se reforce a separação entre conhecimento e cultura. Assim, olha-se para o "daltonismo cultural", procurando outros espaços de dizer que não aqueles da homogeneização e do estereótipo. No entanto, nesse mesmo dizer opera, como por um lapso, esse mesmo mecanismo de legitimação, que produz a divisão entre o especialista e o artífice, fazendo funcionar aquelas relações de poder que determinam os que dizem o que fazer e aqueles que ouvem e agem; legitimação que, em outro espaço, permite falar de "indesejáveis influências".

Há nesse dizer, entendemos, uma ruptura provocada pela ideia de neutralização que parece fazer furo em um discurso sobre a cultura no qual se acenava para o seu caráter crítico, para o acolhimento da cultura nos ambientes educativos como possibilidade de olhar para a diversidade. Talvez esteja nessa ruptura um sinal de que pensar a cultura exige um olhar para a complexidade dos processos identificatórios por que passa o sujeito, porque isso nos permite lembrar que não é possível uma identificação compulsória com a cultura, ou a adesão "consciente" a esses lugares. Essa relação, que comporta outras dimensões, dimensões de outra ordem - porque falar da relação entre sujeito e cultura é falar da dinâmica entre o social e o individual no discurso -, coloca à mostra o fato de que o mecanismo de (des)conhecimento sobre o qual nos falava Pêcheux opera, como bem nos ensinou, instaurando o espaço da contradição, e nesse, caso, trazendo à tona o trabalho de naturalização que produz a cultura, e cujo efeito é apagar em nosso dizer o funcionamento de 'juízos de valor', nos termos de Eagleton, que inevitavelmente atravessam o nosso olhar, determinando, por exemplo, o que se pode incorporar e o que deve ser neutralizado.

Certamente compartilhar da cultura é ter a possibilidade de viver em sociedade, de ser aceito por determinado grupo social, mas não podemos esquecer que pensar na neutralização de influências (não importando de onde elas venham) é reforçar um desejo de harmonizar o diverso, de controlar a dispersão, que nos parece mais um meio de regulação de comportamentos sociais, do que um olhar crítico sobre a cultura e os processos culturais. Por isso é tão importante que insistamos na dimensão políticohistórico-social da cultura, sob pena de cairmos outra vez no campo dos julgamentos sobre a inferioridade/superioridade de certas manifestações culturais e/ou formas de se relacionar com a cultura.

E isso, entendemos, é olhar para a cultura como lugar de interpretação, evitando, como propôs Bosi (2003), pensá-la como um espetáculo de variedades, aceitando o lugar de espectadores, ou seja, considerando as manifestações culturais como retratos

\footnotetext{
8 É interessante pensarmos que a própria noção de respeito aos valores culturais precisa, quando assumimos a cultura como um lugar de interpretação, assume outras dimensões, teóricas, mas também políticas, porque a relação do sujeito com a cultura passa por processos de identificação, e, portanto, de não-identificação.
} 
fixos de uma diversidade que está aí para ser observada e assimilada. Longe disso, o olhar que convocamos é aquele para o qual essas representações são signos de uma identidade em eterna construção. Sem esse olhar, corremos o risco de deixar que atravesse as nossas práticas o já tão criticado dizer que insiste na divisão entre os que têm cultura e os que não a possuem, discurso que longe de instaurar espaços de resistência, reforça divisões, tão semelhante a um outro discurso para o qual olhou Chauí (2006), e que também remete a divisão social do trabalho, aquele da ideologia da competência, que separa os que sabem, e por isso, em suas palavras, mandam, e os que não sabem, e por isso obedecem.

Por fim, se ainda há muito nos documentos dirigidos aos professores para se explorar - como uma insistência resistente na ação consciente e segura do sujeito, que chama para um olhar cuidadoso para o modo como são construídos os lugares do professor e a própria configuração dos ambientes escolares nesses documentos, como as aspas abundantes que remetem para sentidos à deriva -, entendemos que - apesar das contradições ou justamente por elas - eles trazem uma contribuição importante no sentido de instaurar um espaço de elaboração conceitual. Esse é um movimento indispensável se o que se deseja é que os ambientes educativos tornem-se lugares nos quais os sujeitos encontrem espaços de dizer, em que possam assumir efetivamente um lugar no discurso. Assim, embora muito se diga, ainda, nesses documentos, sobre o professor e para ele, pode-se dizer que eles se constituem como brechas, embora por vezes tímidas, para que se passe da pura e simples formação para uma reconfiguração das práticas e dos espaços de aprendizagens. Importante é não apagar as contradições ou subestimar seus efeitos.

\section{BIBLIOGRAFIA}

BERTOLDO, E. S. Políticas de formação de professor de língua e seu impacto no sujeito-professor. In. INDURSKY, F.; FERREIRA, M. C. L. (Org.). Análise do discurso no Brasil: mapeando conceitos, confrontando limites. São Carlos: Claraluz, 2007, p. 145-152.

BOSI, A. Plural mas não caótico. In.___. Cultura brasileira. Temas e situações. 4 ed. São Paulo: Ática, 2000, p. 7-16.

CHAUÍ, M. Cidadania cultural. O direito à cultura. São Paulo: Editora Fundação Perseu Abramo, 2006.

DE NARDI, F. S. Um olhar discursivo sobre língua, cultura e identidade: reflexões sobre o livro didático para o ensino de espanhol como língua estrangeira. Tese de Doutorado. Universidade Federal do Rio Grande do Sul, 2007.

EAGLETON, T. A idéia de cultura. São Paulo: Unesp, 2005.

FUKS, B. B. Freud e a cultura. Rio de Janeiro: Jorge Zahar, 2003.

MOREIRA, A. F.; CANDAU, V. M. Indagações sobre o currículo: currículo, conhecimento e cultura. Brasília: Ministério da Educação, Secretaria da Educação Básica, 2008.

PÊCHEUX, M. O mecanismo do (des)conhecimento ideológico. In. ZIZEK, S. (org.). Um mapa da ideologia. Rio de Janeiro: Contraponto, 1996, p. 143-152.

Obras consultadas: 
HALL, S. A identidade cultural na pós-modernidade. 7. ed. Rio de Janeiro: DP\&A, 2003.

MUTTI, R. M. V. O professor e a constituição de nova posição no discurso pedagógico. In: ERNEST-PEREIRA, A.; MUTTI, R. V. (Orgs.). Práticas discursivas. Pelotas, RS: EDUCAT, 2008, p. 143-164.

PÊCHEUX, M. (1983) O discurso: estrutura ou acontecimento. São Paulo: Pontes, 1990. 